\title{
Recent Development in Treatment of Malaria
}

\author{
Rahul Shukla $^{1 *}$, Rishabh Gupta ${ }^{2}$ and Shweta ${ }^{1}$ \\ ${ }^{1}$ Sri Venkateshwara University, India \\ ${ }^{2}$ Amity Institute of Pharmacy, Amity University, India
}

Submission: February 02, 2018; Published: February 23, 2018

*Corresponding author: Rahul Shukla, School of Pharmaceutical Science, Shri Venkateshwara University, Amroha, Gajraula, Uttar Pradesh, India, Tel: 9889670906; Email: shuklarhl@gmail.com

\begin{abstract}
Malaria is a disease caused by female anopheles' mosquito and is a life- threatening disease. It is spread through bite of mosquito. Anopheles mosquito that transmit malaria have five different species of plasmodium (Plasmodium falciparum, Plasmodium vivax, Plasmodium ovale, Plasmodium malariae \& Plasmodium knowlesi). According to data provided by World Health Organization (WHO), it can be estimated simply that 3.2 billion people are at the risk of malaria. The chances of infection with plasmodium species is mostly at the time of dawn and dusk and is very less or rare at day time.

Anti-malarial medications are used from early times and the most common and well known anti- malarial drug is Quinine that is isolated from cinchona bark in the year 1820. Quinine is the first anti-malarial drug to be used that is more effective than any other anti-malarial drugs in early 1600 s. Our scientist searching for anti-malarial drug that effects the pathway of malarial parasite in a single dose only, this will help in treating patients to a large extent and in a very short duration of time. According to WHO, it has been estimated that malaria will be eradicated completely by 2050 .
\end{abstract}

Now, it is a topic of world's health concern that how it can be completely eradicated. According to a journal "Pathogens and Global Health", it is seen that maternal education can be very helpful and can act as a "Social Vaccine" specially for children in eradicating malaria among young age of children.

\section{Introduction}

The name Malaria comes from the Italian word "mal + aria" means bad air.

Malaria is a disease caused by female anopheles' mosquito and is a life- threatening disease. It is spread through bite of mosquito. Anopheles mosquito that transmit malaria have five different species of plasmodium. These species can be mentioned as-

\section{a) Plasmodium falciparum \\ b) Plasmodium vivax \\ c) Plasmodium ovale \\ d) Plasmodium malariae \\ e) Plasmodium knowlesi}

Plasmodium knowlesi is very less known species of plasmodium as that of other plasmodium species, it infects human occasionally and its mode of transmission is also unclear.

The species of plasmodium that causes malaria are single celled organisms that needs a host body to survive. These species are non-living outside the host body and these cannot infect person with malaria until they are outside the host body because their lifecycle is incomplete without a human host. The malarial parasite gets their nutrition from Red Blood Cells (RBCs) that are present in the blood of human host. 'Out of these five species of plasmodium, Plasmodium falciparum is a life-threatening species causing malaria to a wide range across India and also worldwide [1].

It is considered to be very prevalent in Sub-African countries. The other four species of plasmodium are not so much lifethreatening as that of Plasmodium falciparum. The second most effective species is Plasmodium vivax and it is very much prevalent in South-East Asia and parts of Latin America.

Plasmodium vivax and Plasmodium ovale can cause severe complications and together it is very dominant in case of dormant liver stage. The clear mode of transmission is unclear specifically in case of Plasmodium knowlesi species. According to data provided by World Health Organization (WHO), it can be estimated simply that 3.2 billion people are [2] (Figure 1).

at the risk of malaria. The chances of infection with plasmodium species is mostly at the time of dawn and dusk and is very less or rare at day time. If it is not treated, it can be very 
critical due to high rate of reproduction of parasite in the blood stream of the host. Female anopheles' mosquito bites mostly between $9 \mathrm{pm}$ - 5am and it is the main reason why people are suggested/advised to sleep under mosquito net in this particular duration of time to prevent occurrence of malaria [3].

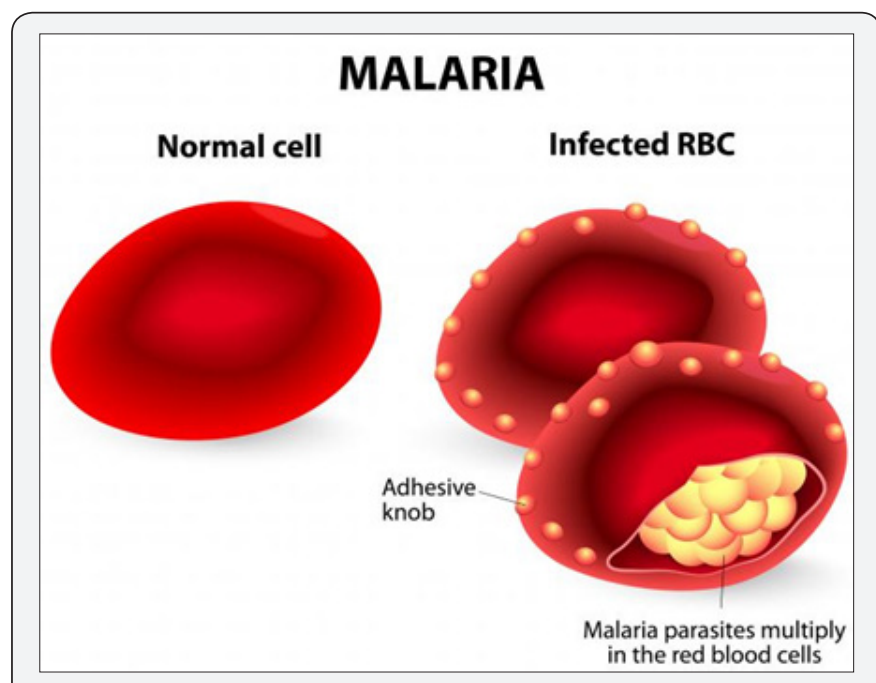

Figure 1: at the risk of malaria. The chances of infection with plasmodium species is mostly at the time of dawn and dusk and is very less or rare at day time.

\section{Causes of Malaria}
a) Organ transplant
b) Transfusion
c) Use of shared needles and syringes
d) Bite of female anopheles; mosquito
e) Humidity and ambient temperatures
f) Movement to areas that are endemic to malaria

\section{Symptoms of Malaria}
a) High fever
b) Profuse sweating
c) Headache
d) Nausea
e) Vomiting
f) Muscle pain
g) Convulsions
h) Bloody stools
i) Deep breathing and respiratory distress
j) Abnormal bleeding
k) Vital organ dysfunction
l) Symptoms begin 10 days to 4 weeks after infection

m) In some patient's symptoms may be seen after 7 days of infection with malaria [4].

\section{Diagnosis and Treatment}

a) Health history.

b) Travelling details of different tropical climates and endemic areas in last few months.

c) Diagnosis of enlarged liver or spleen.

d) Blood test [5].

e) The treatment that is available and is most effective in case of Plasmodium falciparum species is Artimisinin based Combination Therapy (ACT).

There are vaccines that are also available in the market for the treatment of malaria. One of such vaccines is RTS, S/AS01it is also called as Mosquirix used for curing malaria inn young children. Increasing access to ACTs has been integral to the world wide fight against the disease [6].

\section{Anti-Malarial Medications}

Anti-malarial medications are used from early times and the most common and well known anti- malarial drug is Quinine that is isolated from cinchona bark in the year 1820 [7] (Figure 2). Quinine is the first anti-malarial drug to be used that is more effective than any other anti-malarial drugs in early 1600 s. Quinine is mostly effective against vivax and malariae species of plasmodium. One of the derived product from Quinine is Chloroquine that is effective against falciparum species. Quinine is very much effective in persons who are coming from places where malaria is very prevalent [8].

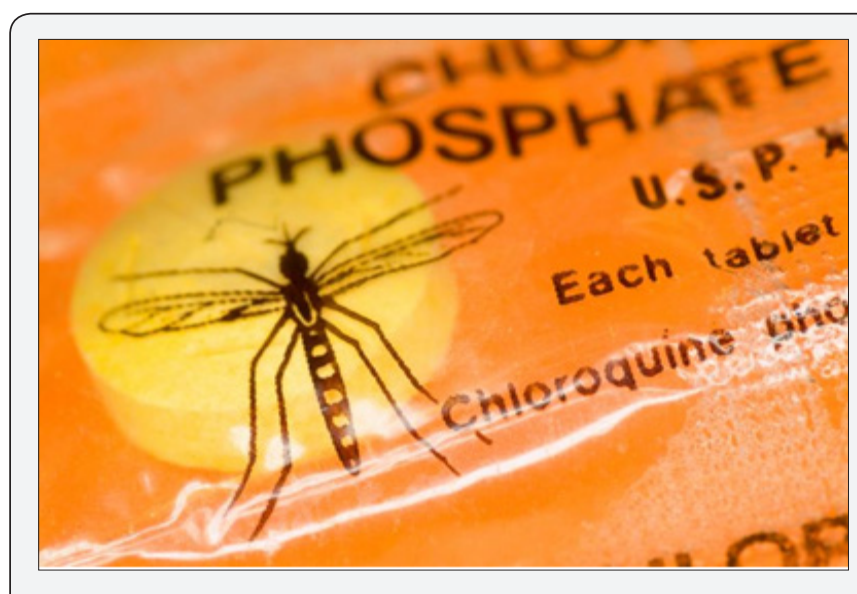

Figure 2 : Anti-Malarial Medications.

The dose of Quinine is $20 \mathrm{mg} / \mathrm{Kg}$ for first time and $10 \mathrm{mg} /$ $\mathrm{Kg}$ at an interval of every 8 hours for 5 days. These dose can be administered through intra-venous, oral and intra- muscular routes of drug administration [9].

\section{Classification of Anti- Malarial Drugs}

a) Aryl amino alcohols: Quinine, Quinidine 
b) 4 -amino quinolones: Chloroquine, Amodiaquine

c) Folate synthesis inhibitor: Proguanil, Pyrimethamine d) 8 - amino quinolones: Primaquine

e) Anti microbials: Clindamycin $[10,11]$.

\section{Recent Development in the Treatment/Medication System to Eradicate Malaria}

\section{New single dose malaria treatment: Offers hope for malarial patients; A step towards eradication}

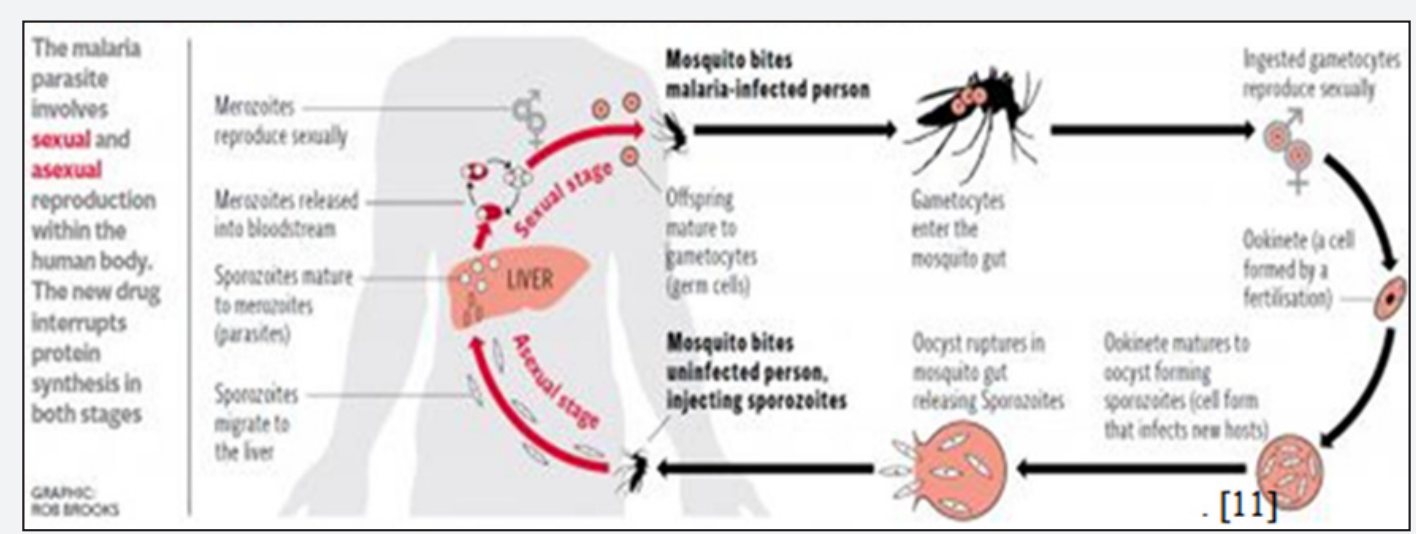

Figure 3 : Malaria's life cycle a completed chain could now be broken.

Our scientist searching for anti-malarial drug that effects the pathway of malarial parasite in a single dose only, this will help in treating patients to a large extent and in a very short duration of time. The drug compound that scientist have developed recently is a synthetic compound and stops the further processing of life cycle at various stages of the malarial cell cycle [12] (Figure 3).

From a research, it has been found that the newly developed compound i.e., (DDD107498) helps to cure infection caused by malarial parasite effectively in animal models like mouse and it also helps in preventing human host from acquiring the infection. Malaria proves to be a life-threatening and deadly disease. It infects around 1-2 million peoples and also cause death of more than half millions of peoples mostly in Sub-African countries [13].

Children under the age of five years and pregnant women are more at the risk of getting infected with malaria easily. According to a report provided by WHO one child every minute dies from severe malaria. Therefore, there is so much requirement of development of new medication/treatment and this recently developed compound (DDD107498) is very essential and found to be showing good effectiveness against rapid resistance of malarial parasite.

This newly developed synthetic drug compound can prevent resistance of malarial parasite to drug compound due to its alternative mechanism of action to treat malaria. The compound recently developed (DDD107498) can be used with other antimalarial drug to increase effect in combination and reduce the risk of getting resistance to medication provided [14].

It has wide range of activity against the malarial parasite and currently known to be more effective than any other antimalarial drugs that are used these days. The recently developed compound inhibit the translation elongation factor eEF2 found in the parasite that is responsible for protein synthesis in the malarial parasite. The eEF2 is the main site of target for drug compound and it also demonstrate a potential new drug site [15].

If this compound successfully launched in the market and is effective against the required cause, then the drug cost around US $\$ 1$ that can be easily affordable by large number of patients suffering from malaria in developing countries, more than that of developed countries. Including this drug compound (DDD107498), there are some more compounds that has been developed recently against the malaria for its eradication mostly from developing countries [16].

Swiss non-profit organization recently developed a new drug compound ELQ-300. This ELQ-300 cause interruption in the life cycle of malarial parasite by disabling the mitochondria of the plasmodium cells. The person does not experience any symptoms because the parasite is destroyed. This ELQ-300 also stops transmission of malaria from one person to another because no active species are present in the blood stream of the human host due to administration of ELQ-300. This drug ELQ300 is thirty times more effective than any other drugs recently used in the treatment of malaria is mainly Atovaquone [17]. This recently developed drug is mainly effective majorly because of two reasons:

a. This drug compound kills the malarial parasite in all three stages of life cycle and also maintains potency of drug over extended period of time.

b. This drug is effective in disabling mitochondria of the malarial parasite without effecting the human cells.

This drug works in very less dose than any other antimalarial drug currently in use and is also patient compatible 
in terms of low dose cheaper cost than any other anti-malarial drugs and can be easily affordable by large population suffering from malaria.

Two more drugs recently developed i.e., KAE609 and KAF156. KAE609 can be one of the novel drug compound introduced for the treatment of malaria in decades. It is effective against two primary malarial parasite causing malaria and also prevents resistance of drug compound to the disease [18]. This drug KAE609 is mostly effective against vivax species in South America and Asia While African countries are highly effected by falciparum species.

KAF156 is an "imidazole piperazine" that has been discovered in 2008 by Novartis. KAF156 is effective in killing malarial parasite when they are in their primary stage i.e., in liver cells. This prevents transmission of parasites to blood stream where it causes most of the damage to the human. Therefore, it can be serve as prophylactic treatment. This is considered to be key activity that is additionally present in KAF156 in comparison to that of previously use Artemisinin based Combination Therapies (ACTs) [19].

\section{Expansion of Access to Artemisinin Based} Combination Therapies (Acts)

In recent years, there is frequent increase in the access of Artemisinin based Combination Therapies (ACTs). According to a study, it has been estimated that by the end of 2014 ACTs has been picked up by the people as first line treatment for curing malaria in 81 countries.

In the year $2013 \& 2014,392$ million and 337 million ACTs treatment courses respectively were provided to both public areas and private sectors in endemic areas. These treatment courses progress in the country as well as globally in accessing diagnosis and anti-malarial treatment that proves to be very effective [20].

\section{Newly Developed Anti-Malarial Treats Toxoplasmosis}

A new anti-malarial drug that will shortly enter in clinical trial phase for treatment of malaria is 10 times more effective drug for the treatment of toxoplasmosis, that effects almost 2 billion peoples globally [21]. A researchers' team from University of Chicago Medical Centre launched a drug in the market known as JPC-2056 is highly effective against Toxoplasmosis gondii, a parasite that causes Toxoplasmosis and it does not cause any toxicity or side effects as a result of drug administration.

Until JPC-2056 has not come into existence, Pyrimethamine and sulfadiazine are being used to treat toxoplasmosis. The route of administration of JPC-2056 is oral route, it is bioavailable for action in the body and is non-toxic and it is very effective against the disease causing parasite in just few days. This Drugs blocks dihydrofolate reductase enzyme (DHFR) that is being produced by group of parasites causing toxoplasmosis and malaria. It is very different from human dihydrofolate reductase (DHRF). This drug is also effective against malarial parasite that cause frequent mutations and thus get resistance to medication provided for treatment of malaria [22].

\section{Economic Prospects for New Anti-Malarial Drugs}

From the prospects of economy, the market for anti-malarial medication having 2.8 billion people living in the highly malaria effected areas and about 20-30 million peoples are Europeans and North Americans, that either live or travel to endemic areas of malaria and they prove to be a good source for transmitting malaria specially in developing countries [23].

Around 1.9 billion peoples are exposed to malaria in some of largest markets that include China, India and Indonesia while around 400 million peoples in Sub-Saharan African countries. According to an estimation around 200 million cases of malaria occur each year with 2 million people dying every year as a cause of suffering from severe malarial symptoms and these deaths more frequently occur in African children as they are more prone to the disease [24].

The anti-malarial drugs that are distributed through different networks are purchased by government bodies and some of the private organizations. In the current world market chloroquine dominates the market because of its wide range of availability, its safety and low prices. National control programme distribute around 20 percent of the total chloroquine production and 80 percent of the chloroquine production was distributed by various other channels.

Chloroquine is probably second or third most used drug for treatment of malaria worldwide. The global market for chloroquine is around US\$ 64-80 million and sulfadoxine/ Pyrimethamine is about US\$20 million from the total world market of US\$100-120 million [25].

\section{Ranbaxy Launches New Anti-Malarial Synriam}

Synriam newly synthesized drugs by Ranbaxy claims to be more effective and simpler medication for malaria than any other drug and this medication is developed so that it is not based on Artemisinin that starts developing resistance against malaria. But none of the active ingredients of Synriam were developed in the country. Synriam is a combination of arterolane maleate and piperaquine phosphate, in which arterolane is newly synthesized/developed chemical entity.

According to the reports produced by Ranbaxy, this Synriam cures $95 \%$ of the disease when 3 tablets were taken in the duration of 3 days, this is much simpler drug regimen than any other treatments. The need to develop this type of medication is very much necessary because Artemisinin is still produced from plant sources, that makes it expensive, as well as it easily develop resistance against malaria.

Whereas, Arterolane is much easier to synthesize and it can be sold at less than $\$ 3$ a course and one benefit of using Arterolane is that it prevents developing resistance against 
malaria. Arterolane was discovered by a collaborative, drug discovery project funded by Medicines for Malaria Venture (MMV), a Swiss charity.

Arterolane consist of admantane and an ozonide in its structure. According, to the news provided by Ranbaxy, it tries to introduce Synriam in endemic areas of malaria with high efficacy and affordable price so that a wide range of people suffering from disease can get access to the medication. According to WHO, it has been estimated that malaria will be eradicated completely by 2050 [26].

\section{A Recombinant Blood Stage Malaria Vaccine Reduces Plasmodium falciparum Species}

The vaccine for malaria that is designed recently have a combination of surface antigen that is found on infected erythrocyte ring of the species of plasmodium falciparum and two surface proteins (MSP1 \& MSP2). This trial is conducted in 120 children and 62 percent of which are found to have reduced percentage of parasite density, even though these children are not pre-treated with medications like Pyrimethamine-sulphadoxine.

This vaccine combination is also effective in the patients that are previously exposed to malaria and this shows that the vaccine combination is effective against plasmodium falciparum species [27]. This vaccine combination will prove as costeffective and will be a great help with the vaccines that are already present in the market for the treatment of malaria. This vaccine combination $\mathrm{B}$ laid emphasis on reducing growth and multiplication of parasite in the blood itself so it does not circulate to all other body parts through blood circulation and hence it will reduce severity of symptoms that are caused by malarial parasites mostly in Sub-African countries in younger children and helps to reduce morbidity and mortality rate in these endemic areas [28].

To determine the prevalence, new infections and parasite genotype, a technique was developed that is known as Polymerase Chain reaction (PCR). The samples of blood that are collected from infected persons during the trial period are genotyped with the help of highly polymorphic msp2 locus as a marker.

Only 3D7 form of msp2 was included in the combination B vaccine and thus, if vaccine proves to be efficacious, there will be specific effect that are expected to be effective against the genotype of the malarial parasite. Although this combination $\mathrm{B}$ vaccine is highly effective but it is observed that the morbidity rate increases frequently in the year of conducting this clinical trial for combination B vaccine. This is the topic of concern for everyone taking part in the trials.

Along with combination B vaccine, Vitamin A supplements were also provided and a change was observed that there is reduction in the morbidity rate and parasite density in the children of age group 6 months- 4 years old. According to a study it is found that msp2 FC27-type infections are more complicated than 3D7-type infections. The vaccines that are provided for the treatment of 3D7-type infections seems to favour the growth and development of FC27-type parasites and hence increases the morbidity rate in the patients that are provided with the vaccine that are used to treat FC27-type infection more frequently in children of the age group nearly from 6 months- 4 years [29].

\section{Vaccines against Parasites}

The vaccines that are currently in use are divided into three categories i.e., attenuated microbes, protein sub units and killed microbes. An attenuated vaccine is that which is created by reducing virulence of causative parasite but still keeping it alive, killed microbes are used earlier and vaccines that use these killed microbes are polio vaccines.

The most recent vaccines that are prepared using protein subunits proves to be very effective against encapsulated bacterial pathogens. But, the vaccines that are developed by using protein subunits are very less in number. The parasites that are used to produce malarial vaccines faces a problem that these parasites produce very less immunity i.e., not effective against plasmodium falciparum species. This proves to be a challenge in the preparation of vaccine.

\section{Mosquito Stage Vaccines}

Producing vaccines against malarial parasites prevention is the potential approach, but it is observed and is surprising that it is not supported largely till now. The main issue of concern is that the population that is provided vaccination can transmit malarial parasite from one person to another. It can either be adults, infants, young children. So, to reduce this problem of transmission, the persons that are provided vaccination should be resident of an area where reduction of transmission can be easily accessible and it should not be transmitted to healthy population.

Because if the persons that are provided vaccinations are from different places, then it can be difficult to control transmission and hence, it will be very challenging to stop or reduce transmission among peoples. The true mosquito vaccine has a specific advantage that it is highly effective against more than one plasmodium species, this effect is not being produced by any other vaccines that are used for the treatment of malaria.

This encouragement, increases the interest to develop more candidate of mosquito stage vaccines, some of which can act as several stages of malarial cycle and can be effective at different stages of malarial cycle and also to reduce transmission level. Malaria killed more than 429,000 people in Europe in 2015, many of them were children from sub-African countries. The scientists and researchers are still searching for newer highly effective and potent vaccine which have its long term effect [30].

\section{Could there be a 'Social Vaccine' for Malaria?}

Malaria is one of the life-threatening disease that every two minutes a death occurs due to malaria mostly in children of Sub- 
Saharan African countries. This disease has mortality rate of 200 million peoples globally each year. 90 percent of whom are young children under the age of 6 years.

Now, it is a topic of world's health concern that how it can be completely eradicated. According to a journal "Pathogens and Global Health", it is seen that maternal education can be very helpful and can act as a "Social Vaccine" specially for children in eradicating malaria among young age of children. The researchers done a survey with children parents to know about knowledge and awareness of parents regarding preventive measures that can be taken to avoid malarial infections in their children in endemic areas. This survey enquires about parent's education level, using of bed nets, their socio-economic status.

It has been concluded from the survey that the higher will be mother's education and awareness regarding malaria, lesser will be the chances of the infection to their children with malaria. According to numerically estimated data, it has been figured out that 123 out of 647 children have given positive result for malaria. The level of prevalence frequently dropping down with increase in the education level of children mother's.

The children whose mothers doesn't have any education have prevalence to malaria nearly about 30 percent, whereas the rate drops down to 17 percent in the children whose mothers receives primary education and 15 percent in those children whose mothers received education beyond primary schooling. This shows that higher education level is very much necessary in preventing malaria in children in endemic areas. It is important to use bed nets and take care of your child when suffering from fever mostly in areas endemic to malaria [31].

\section{Researchers Discover 'map' In Malarial Vaccine Hunt}

There are numerous vaccines that are present for preventing malaria but this time researcher reached to the molecular level of the deadliest parasite causing malaria in endemic areas mostly in Sub-Saharan African countries. The researchers found parasite protein CyRPA details at atomic level for the first time and find out how antibodies block the function of CyRPA to bind and infect the human red blood cells.

CyRPA a protein found in malarial parasite forms a complex with two other parasite proteins that are- PfRh5 and PfRipr and this complex is very much necessary for the parasite to enter and bind to red blood cells. According to Professor Cowman, he and his team spend 30 years in unrevealing this fact about invasion of malarial parasite to human host.

According to this research, it has been shown how antibodies block malaria parasite to infect human RBCs which was previously unknown. Antibodies to CyRPA act as a shield, and do not permit interaction with its protein part i.e., PfRh5 and stops the parasite in its path.

This binding of CyRPA to PfRh5 is very much essential for parasite survival and by blocking interaction, CyRPA act as a potent malarial vaccine candidate. According to another research, it has been seen that there is one more protein that is responsible for causing malaria. From this research, it is seen that malarial parasite needs RH5 protein to bind to basigin receptor on the surface of red blood cells.

In the recent studies, it has been found that a protein P113 that is present on parasite surface are needed to capture RH5 protein for binding to basigin protein on the surface of red blood cells. RH5 and P113 protein work together to invade human red blood cells. But recently developed antibodies are able to block P113 protein to prevent binding of RH5 to P113 and thus preventing invasion of human red blood cells [32].

\section{Malaria Vaccine Candidate Produced From Algae}

The team of researchers at University of California used Algae as a source of producing malarial parasite protein. This approach of researchers is to avoid transmission of malarial parasite from infected human to mosquitoes. For producing large quantity of Pfs25, a protein found on reproductive cells of malarial parasites, researchers find it difficult to produce large quantities of Pfs 25 in laboratories.

So, they inserted DNA of gene of Pfs25 into plant cell nucleus and with increase in time algae starts growing more and replicating. In this way the team of researchers were able to purify enough functional Pfs 25 proteins for laboratory testing.

Algae is very well known for producing various protein source, it is also very cheap, environment friendly and easily accessible source of vaccine production. The only need is simple chemicals to feed algae for its replication, growth and folding of proteins. We can easily have scaled up the production of desired proteins. Mosquito were fed parasites in the parasites in the presence of immune serum in mice vaccinated with algae that produce Pfs 25 in presence of new adjuvant.

After 8 days, researchers examined mosquito's gut for the presence of malaria parasite and the results found were drastic, only 1 out of 24 (4.26 percent) mosquitoes that consumed Pfs 25 serum was positive for the malarial parasite. As there is very low cost required for the production of algae, so it can be the only source that will be very helpful in producing economic malarial vaccines [33].

\section{Conclusion}

As we know that malaria is a life-threatening disease that affects a large portion of Sub-Saharan African countries. African countries are very endemic to malaria. But with this increase in malaria level, our scientist and researchers are also working very hard to overcome this life threatening disease. There is recent development in the treatment of malaria. Scientist discover new medications and vaccines that can be prepared easily and in less duration and the main objective of scientists and researchers is that they can make these medications easily available to most of the malaria suffering patients that can easily afford medication. 
From the prospects of economy, the market for anti-malarial medication having 2.8 billion people living in the highly malaria effected areas and about 20-30 million peoples are Europeans and North Americans, that either live or travel to endemic areas of malaria and they prove to be a good source for transmitting malaria specially in developing countries.

Surveys are organized to have a check on the progress of recent medication that are developed. Based on these surveys, it has been estimated that malaria will be eradicated completely from the world by 2050 . The scientists and researchers are still searching for newer highly effective and potent vaccine which have its long term effect.

\section{References}

1. http://www.healthline.com/health/malaria

2. Warrell DA, Timothy MC, John DF (2017) Oxford textbook of medicine. In: (5th edn), Oxford Medicine online, UK.

3. https://www.malarianomore.org/pages/what-is-malaria

4. Piola P, Nabasumba C, Turyakira E, Dhorda M, Lindegardh N, et al (2010) Efficacy and safety of artemether-lumefantrine compared with quinine in pregnant women with uncomplicated Plasmodium falciparum malaria: an open-label, randomised, non-inferiority trial. Lancet Infect Dis 10(11): 762-769.

5. Gready MR, Lee SJ, Wiladphaingern J, Ashley EA, Rijken MJ, et al. (2012) Adverse effects of falciparum and vivax malaria and the safety of antimalarial treatment in early pregnancy: a population-based study. Lancet Infect Dis 12(5): 388-396.

6. Mehra N, Bhasin VK (1993) In vitro gametocytocidal activity of artemisinin and its derivatives on Plasmodium falciparum. Jpn J Med Sci Biol 46(1): 37-43.

7. Ballestero JA, Plazas PV, Kracun S, Gómez-Casati ME, Taranda J, et al (2005) Effects of Quinine, Quinidine, and Chloroquine on $\alpha 9 \alpha 10$ Nicotinic Cholinergic Receptors. Molecular Pharmacology 68(3): 822-829.

8. https://www.google.co.in/search?q=areas+affected+by+malar$i a+i n+i n d i a \&$ source $=\operatorname{lnms} \&$ tbm $=i s c h \& s a=X \& v e d=0$ ahUKEwjv7 $c P N x-$ pbUAhUJto8KHbrZCOIQ_AUICigB\&biw=1366\&bih=589\#imgrc=UIILWiNMqWTQ8M

9. http://www.fitfortravel.nhs.uk/destinations/asia-(east)/india/india-malaria-map.aspx

10. https://www.google.co.in/search?q=areas+affected+by+malaria + in + india\&source $=\operatorname{lnm} s \& t b m=i s c h \& s a=X \& v e d=0$ ahUKEwjv7cPNxpbUAhUJ to 8KHbrZCOIQ_AUICigB\&biw $=1366 \& \mathrm{bih}=589 \#$ tb $\mathrm{m}=$ is ch\& $q=$ malaria + endemic + countries $+i n+$ world $+2015 \&$ imgdii $=$ s0gVzdBTayldM:\&imgrc=CWsGyUUPhwDMrM

11. https://www.google.co.in/search?q=life+cycle+of+malaria\&source=lnms\&tbm=isch\&sa=X\&ved=0ahUKEwiUvPr62pbUAhUFRo8KHSIPBDgQ_AUICigB\&biw $=1366 \&$ bih $=638$

12. David B, Jacoby RMY (2005) Encyclopedia of Family Health.

13. https://www.google.co.in/search?q=recent+medication+for+malar$i a+$ in + market\&oq=recent + medication + for + malaria $+i n+$ market\&aqs $=-$ chrome..69i57.25750j0j8\&sourceid=chrome\&ie=UTF-8

14. Murray CJ, Rosenfeld LC, Lim SS, Andrews KG, Foreman KJ, et al. (2012) Global malaria mortality between 1980 and 2010: a systematic analysis. Lancet 379(9814): 413-431.
15. http://www.healthmap.org/site/diseasedaily/article/new-malaria-drug-step-towards-eradication-32913

16. Vugt VM, Brockman A, Gemperli B, Luxemburger C, Gathmann I, et al. (1998) A randomised comparison of artemether-benflumetol and artesunate-mefloquine in the treatment of multidrug-resistant falciparum malaria. Antimicrob Agents Chemother 42: 135-139.

17. https://www.chemistryworld.com/news/ranbaxy-launches-new-anti-malarial-synriam/4967.article

18. Foster S (1994) Economic prospects for a new antimalarial drug. Trans R Soc Trop Med Hyg 88(Suppl 1): S55-S56.

19. Dondorp AM, Nosten F, Yi P (2009) Artemisinin resistance in Plasmodium falciparum malaria. N Engl J Med 361: 455-467.

20. University of Chicago Medical Center (2008) Newly Developed Anti-malarial Medicine Treats Toxoplasmosis. Science Daily. https:// www.sciencedaily.com/releases/2008/03/080304200908.htm

21. http://www.bbc.com/news/uk-scotland-tayside-central-33164528

22. http://www.independent.co.uk/news/science/scientists-develop-new-malaria-drug-that-treats-symptoms-and-prevents-infection-being-transmitted-10327058.html

23. Genton B, Betuela I, Felger I, Al-Yaman F, Anders RF, et al. (2002) A Recombinant Blood-Stage Malaria Vaccine Reduces Plasmodium falciparum Density and Exerts Selective Pressure on Parasite Populations in a Phase 1-2b Trial in Papua New Guinea. The Journal of Infectious Diseases 185( 6): 820-827.

24. Russell PF, Mohan BN (1942) The immunization of fowls against mosquito-borne Plasmodium gallinaceum by injections of serum and of inactivated homologous sporozoites. J Exp Med 76(5): 477-495.

25. Freund J, Sommer HE, Walter AW (1945) Immunization against malaria: vaccination of ducks with killed parasites incorporated with adjuvants. Science 102(2643): 200-202.

26. Anders RF, Adda CG, Foley M, Norton RS (2010) Recombinant protein vaccines against the asexual blood stages of Plasmodium falciparum. Hum Vaccine 6(1): 39-53.

27.https://www.eurekalert.org/pub_releases/2017-05/idmm-ril053017.php

28. https://www.eurekalert.org/pub_releases/2017-05/uoaf-ctb050917. php

29. Chen L, Xu Y, Wong W, Thompson JK, Healer J, et al. (2017) Structural basis for inhibition of erythrocyte invasion by antibodies toprotein CyRPA. Elife 14(6): e21347.

30. https://phys.org/news/2017-02-malaria-vaccine-invasion-partner-uncovered.html

31. http://www.sciencemag.org/news/2017/01/promising-malaria-vaccine-disables-key-parasite-genes

32. RTC (2015) Efficacy and safety of RTS,S/AS01 malaria vaccine with or without a booster dose in infants and children in Africa: final results of a phase 3 , individually randomised, controlled trial. The Lancet 386(9988: 31-45.

33. https://www.eurekalert.org/pub_releases/2015-02/uoc-mmc021815.php 
CC (P) This work is licensed under Creative Commons Attribution 4.0 License

DOI: 10.19080/JCMAH.2018.05.555671

\section{Your next submission with Juniper Publishers} will reach you the below assets

- Quality Editorial service

- Swift Peer Review

- Reprints availability

- E-prints Service

- Manuscript Podcast for convenient understanding

- Global attainment for your research

- Manuscript accessibility in different formats

(Pdf, E-pub, Full Text, Audio)

- Unceasing customer service

Track the below URL for one-step submission https://juniperpublishers.com/online-submission.php 